\title{
웃 Carbon dioxide laser for corpus callosotomy in the pediatric population
}

\author{
Omar Choudhri, MD, ${ }^{1}$ Robert M. Lober, MD, PhD, ${ }^{1}$ Joaquin Camara-Quintana, BS, ${ }^{1}$ \\ Kristen W. Yeom, MD, ${ }^{2,3}$ Raphael Guzman, MD, ${ }^{1,2,4}$ and Michael S. B. Edwards, MD ${ }^{1,2}$ \\ ${ }^{1}$ Division of Pediatric Neurosurgery, Department of Neurosurgery, ${ }^{3}$ Division of Pediatric Neuroradiology, Department of \\ Radiology, Stanford University School of Medicine, and 'Lucile Packard Children's Hospital at Stanford, California; and \\ ${ }^{4}$ Department of Neurosurgery, Division of Pediatric Neurosurgery, University Children's Hospital of Basel, Switzerland
}

\begin{abstract}
OBJECT The authors describe the application of a flexible $\mathrm{CO}_{2}$ laser for corpus callosotomy in children with epilepsy. METHODS This retrospective case series reviews all cases in which pediatric patients underwent a corpus callosotomy performed using the $\mathrm{CO}_{2}$ OmniGuide laser between May 2005 and October 2012. Data were collected from 8 corpus callosotomy procedures in 6 pediatric patients presenting with medically refractory epilepsy marked by drop attacks.

RESULTS Complete corpus callosotomies were performed in 6 patients ( 3 boys, 3 girls; ages $5-14$ years). In 4 patients the complete callosotomy occurred as a single procedure, and in 2 patients an anterior two-thirds callosotomy was performed first. These 2 patients subsequently required a complete callosotomy due to inadequate control of their drop attacks. In all cases there was clean lesioning of the tract with preservation of the ependymal plane and less inadvertent thermal tissue damage due to low penetration of the laser through cerebrospinal fluid. All patients had resolution or improvement of drop attacks after surgery. No complications were encountered, and imaging demonstrated a clean sectioning of callosal fibers with preservation of normal ventricular anatomy.

CONCLUSIONS These cases illustrate the use of this device in completing corpus callosotomy in pediatric patients. The low-profile laser fiber tip was well suited for working in the depths of the interhemispheric fissure with minimal brain retraction. The flexible $\mathrm{CO}_{2}$ laser allows a precise callosal lesioning through an interhemispheric approach and is a useful adjunct to be employed in these cases.
\end{abstract}

http://thejns.org/doi/abs/10.3171/2014.10.PEDS13498

KEY WORDS carbon dioxide laser; corpus callosotomy; epilepsy surgery; microsurgery

$\mathrm{C}$ ORPUS callosotomy has been a well-established neurosurgical procedure for more than 50 years as a means to curb nonfocal epilepsy, with a specific indication for drop attacks. ${ }^{21-23}$ Dandy completed the first case in 1931, when he sectioned the corpus callosum during resection of a cavum cyst in a 4-year-old boy and unintentionally freed him of a seizure disorder. ${ }^{6} \mathrm{~A}$ formal description of the procedure came from Van Wagenen and Herrin in 1940, when they reported its use in 10 patients with clinically refractory epilepsy. ${ }^{33}$ Since then, the procedure has been employed for drop attacks, atonic seizures, tonic-clonic seizures, Lennox-Gastaut syndrome, and recurrent status epilepticus. ${ }^{1}$
The corpus callosum is one of the major commissural pathways connecting the cerebral hemispheres. Callosotomy works by disconnecting the interhemispheric spread of seizures. It rarely results in a cure, and hence the goal of the procedure is to decrease seizure frequency. While callosotomy improves function and quality of life, patients are expected to remain on an antiepileptic regimen. Patients often continue to have drop attacks and generalized seizures, which are thought to be due to other commissural pathways, such as anterior, posterior, and hippocampal commissures. ${ }^{25}$

Like most seizure surgeries, callosotomy involves sectioning normal axonal fibers, and hence the extent of le- 
sioning required is always in question. A complete callosotomy can lead to variety of disconnection syndromes, such as supplementary motor area syndrome and alien hand syndrome. ${ }^{17}$

The extent of callosotomy is therefore a balance between achieving good seizure control and minimizing sequelae from disconnection syndromes. In most cases, an anterior corpus callosotomy that spares the splenium is adequate as a first step. If the patient remains affected with high seizure frequency, a second surgery attempting complete callosotomy is prudent. ${ }^{34}$ There are also arguments for anterior, posterior, partial, and complete sectioning of the corpus callosum. ${ }^{14,16,28}$

Corpus callosotomy is performed via an interhemispheric approach, and the surgery itself is associated with risks and neurological sequelae. Neurological sequelae separate from disconnection syndromes are often temporary and include paresis of the nondominant limb, gait difficulty, and urinary incontinence. These are thought to be due to parasagittal disconnection and traction on the frontal parasagittal cortex. Given these issues, the optimal operative technique as well as the optimal extent of sectioning for corpus callosotomy remains a debated issue. For instance, there have been surgical, ${ }^{3,16}$ endoscopic, ${ }^{11}$ and radiosurgical ${ }^{7,10}$ corpus callosotomy case series looking at outcomes in children with intractable epilepsy. All of the newer approaches aim to minimize injury to normal brain tissue while working in a narrow surgical corridor.

Laser systems have played an important role in a variety of neurosurgical procedures since the late 1960s. . $^{2,8,8,24,29-31}$ Argon and Nd:YAG (neodymium:yttrium-aluminumgarnet) lasers have been used in neurosurgical operating rooms in the past, but because of their high penetration and collateral tissue damage they failed to gain popularity. ${ }^{27}$ The $\mathrm{CO}_{2}$ laser, however, has favorable features such as absorption by water and minimal thermal penetration. These properties allow its use for varied applications, such as tumor resection, cord detethering, dural closure, and vascular anastomoses. ${ }^{19}$ Although Stellar et al. used the $\mathrm{CO}_{2}$ laser during resection of a glioblastoma in 1970, it failed to gain popularity due to a cumbersome setup and increased operative times. ${ }^{30}$ The original system required a combination of focusing lenses with an application arm, which made it large and ergonomically unattractive.

Recent development of the OmniGuide fiber by Fink and associates at the Massachusetts Institute of Technology (MIT) has reintroduced the $\mathrm{CO}_{2}$ laser to neurosurgery. ${ }^{32}$ In this paper we report the first successful use of a fiberoptic $\mathrm{CO}_{2}$ laser for corpus callosotomy in 6 children with intractable epilepsy, 2 of whom had the initial anterior two-thirds callosotomy completed with bipolar electrocautery. We demonstrate the safety profile of the $\mathrm{CO}_{2}$ laser and describe its major advantages over other microsurgical tools.

\section{Methods}

This retrospective case series reviews all cases involving pediatric patients who underwent corpus callosotomy at Lucile Packard Children's Hospital at Stanford using the $\mathrm{CO}_{2}$ OmniGuide laser between May 2005 and Octo- ber 2012 and was approved by the hospital's institutional review board. Data from 8 corpus callosotomy procedures performed in 6 pediatric patients who presented with medically refractory epilepsy marked by drop attacks were collected from electronic medical records, radiology reports, operative room records, OmniGuide $\mathrm{CO}_{2}$ laser case logs, and pathology records.

\section{Results}

The 6 patients treated ranged in age from 5 to 14 years (mean 9 years) and included 3 boys and 3 girls (Table 1). Two underwent corpus callosotomy involving the anterior two-thirds of the corpus callosum but required a subsequent complete callosotomy due to continued drop attacks. All patients underwent callosotomy through the interhemispheric approach in the supine position. The laser had a Neuro-L fiber in place with a spot size of $320 \mu \mathrm{m}$ $(0.32 \mathrm{~mm})$ at the tip. The power setting of the laser was between 4 and $8 \mathrm{~W}$, and the laser was used in the continuous wave mode. All patients had improvement in the frequency of drop attacks following a complete callosotomy, and no complications were encountered.

\section{Illustrative Cases}

\section{Case 2}

This 5-year-old girl was diagnosed with medically refractory cryptogenic generalized epilepsy (myoclonic astatic seizure disorder) that began at the age of 8 months with generalized tonic-clonic and absence seizures. Her course was complicated by status epilepticus and profound developmental regression at the age of 2. At the time she came to our attention, she was able to walk with a walker and was nonverbal, with only unintelligible vocalizations. She was dependent upon a gastrostomy tube for nutrition and medications. She was having 2-4 seizures per day, manifested as drop attacks, grimacing, foaming at the mouth, circumoral cyanosis, and bilateral flexion and stiffening of all extremities. Her seizures caused her to throw her head forward, and she wore a helmet for protection when walking or out of her wheelchair for other purposes. At age 3 she underwent placement of a vagal nerve stimulator but it did not diminish the frequency or severity of her symptoms.

An MRI study of her brain showed no abnormality (Fig. 1 left). A 24-hour video electroencephalography (EEG) study showed multifocal spike discharges of multiple ictal myoclonic events with a generalized electroencephalographic pattern. Some seizures were relatively subtle, with an arrest of her behavior and her head slowly dropping forward. These were accompanied on EEG by a generalized decrement with shifting minor focal features, but no distinct localized onset. Some events progressed to a more prominent and obvious generalized tonic seizure, with bilateral arm posturing and no consistent lateralizing or localizing features.

Corpus callosotomy was recommended to reduce the number of drop attacks. A complete corpus callosotomy from rostrum to splenium was performed with the flexible $\mathrm{CO}_{2}$ laser (Fig. 1 right). The patient recovered to her neurological baseline postoperatively, and after some small 
TABLE 1. Clinical characteristics of patients of treated with laser callosotomies

\begin{tabular}{|c|c|c|c|c|c|c|}
\hline $\begin{array}{l}\text { Case } \\
\text { No. }\end{array}$ & $\begin{array}{l}\text { Age (yrs) } \\
\text { Sex }\end{array}$ & Diagnosis & $\begin{array}{l}\text { Extent of } \\
\text { Callosotomy }\end{array}$ & $\begin{array}{l}\text { Power Setting } \\
\text { Range (watts) }\end{array}$ & $\begin{array}{l}\text { Follow-Up } \\
\text { (mos) }\end{array}$ & Seizure Control \\
\hline 1 & $13, \mathrm{M}$ & Tuberous sclerosis, drop attacks & Total & $3-6$ & 9 & Improved \\
\hline 2 & $5, F$ & $\begin{array}{l}\text { Developmental delay, drop at- } \\
\text { tacks }\end{array}$ & Total & $4-6$ & 5 & Improved \\
\hline $3^{*}$ & $8, F$ & $\begin{array}{l}\text { Developmental delay, refractory } \\
\text { epilepsy }\end{array}$ & $\begin{array}{l}\text { 1st stage anterior } 2 / 3 \\
\text { 2nd stage total }\end{array}$ & $6-7$ & 1 & $\begin{array}{l}\text { Continued partial sei- } \\
\text { zures, generalized } \\
\text { seizure improved }\end{array}$ \\
\hline $4^{*}$ & $5, F$ & $\begin{array}{l}\text { Refractory epilepsy, drop at- } \\
\text { tacks, cerebral palsy }\end{array}$ & $\begin{array}{l}\text { 1st stage anterior } 2 / 3 \\
\text { 2nd stage total }\end{array}$ & $4-6$ & 6 & Improved drop attacks \\
\hline 5 & $8, M$ & $\begin{array}{l}\text { Severe refractory generalized } \\
\text { epilepsy, developmental de- } \\
\text { lay, drop attacks }\end{array}$ & Total & $6-8$ & 3 & Improved drop attacks \\
\hline 6 & $14, \mathrm{M}$ & $\begin{array}{l}\text { Lennox-Gastaut syndrome, drop } \\
\text { attacks }\end{array}$ & Total & $4-8$ & 10 & Drop attacks stopped \\
\hline
\end{tabular}

seizures in the immediate postoperative period, she had no definitive seizures for 5 days. On the 5 th postoperative day she was discharged to her home in good condition. At a 4-month postoperative visit, she continued to be free of drop attacks and her other episodes diminished in frequency. The patient began using her left hand with more purposeful and coordinated movements and she was more stable in the sitting position. Her vocalizations increased and she seemed to interact more with her environment. She continued treatment with the same antiepileptic medications.

\section{Case 3}

This 8-year-old girl with developmental delay was originally transferred to our facility for management of status epilepticus. She had previously undergone an anterior two-thirds corpus callosotomy for worsening seizure frequency and drop attacks approximately every 30 seconds as well as neurological decline, which included worsening ataxia that interfered with her ability to walk independently and feed herself. She had a gastrostomy tube in place for feeding before the first callosotomy. Initially, she showed
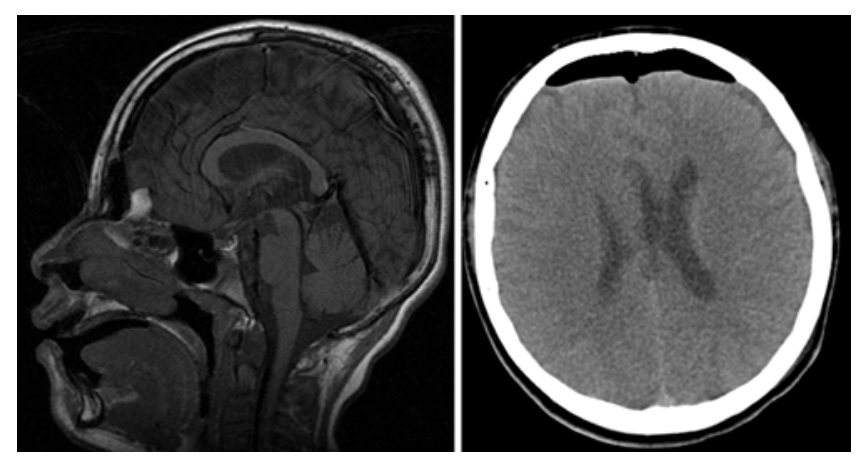

FIG. 1. Case 2. Left: Preoperative sagittal T1-weighted MR image demonstrating an intact corpus callosum with no abnormalities. Right: Postoperative axial noncontrast CT image showing the site of corpus callosotomy with mild bifrontal pneumocephalus. improvement postoperatively, with no seizures for several months, but returned to her preoperative condition about 6 months later.

The remainder of her corpus callosotomy was performed with the $\mathrm{CO}_{2}$ laser; she tolerated the procedure well and there were no complications. Following completion of the callosotomy, she was noted to be much more awake and was smiling. She was able to follow commands in all 4 extremities. She had improvement in swallowing, with most of her nutritional intake being by mouth and only medications administered through the gastrostomy tube. She continued to have frequent small right-sided partial seizures, but they were clearly less severe, and there were almost no generalized seizures. She was interactive, able to walk, and was working with physical and occupational therapists to regain mobility.

\section{Case 5}

This 8-year-old boy had medically refractory epilepsy and associated drop attacks, global developmental delay, and spastic diplegic cerebral palsy. In addition, because of food aversion, he had a gastrostomy tube in place. He was referred to us because he was having 20-30 seizures daily with drop attacks. His MRI showed no abnormality and EEG revealed bilateral frontal and independent bilateral epileptiform discharges along with generalized spikewave discharges. He underwent complete corpus callosotomy from rostrum to splenium. The procedure was well tolerated, and the patient's drop attacks improved significantly postoperatively.

\section{Flexible $\mathrm{CO}_{2}$ OmniGuide Laser}

The OmniGuide $\mathrm{CO}_{2}$ laser (Fig. 2) is a novel, flexible, hollow fiber lined by reflecting dielectric mirror surfaces that allow efficient conduction of energy. The fiber is cooled by an inert helium gas that dissipates the smoke and improves visualization of the beam. The fiber is coupled to a narrow-profile straight or bayoneted handpiece that allows precise control and focus of the target beam as 

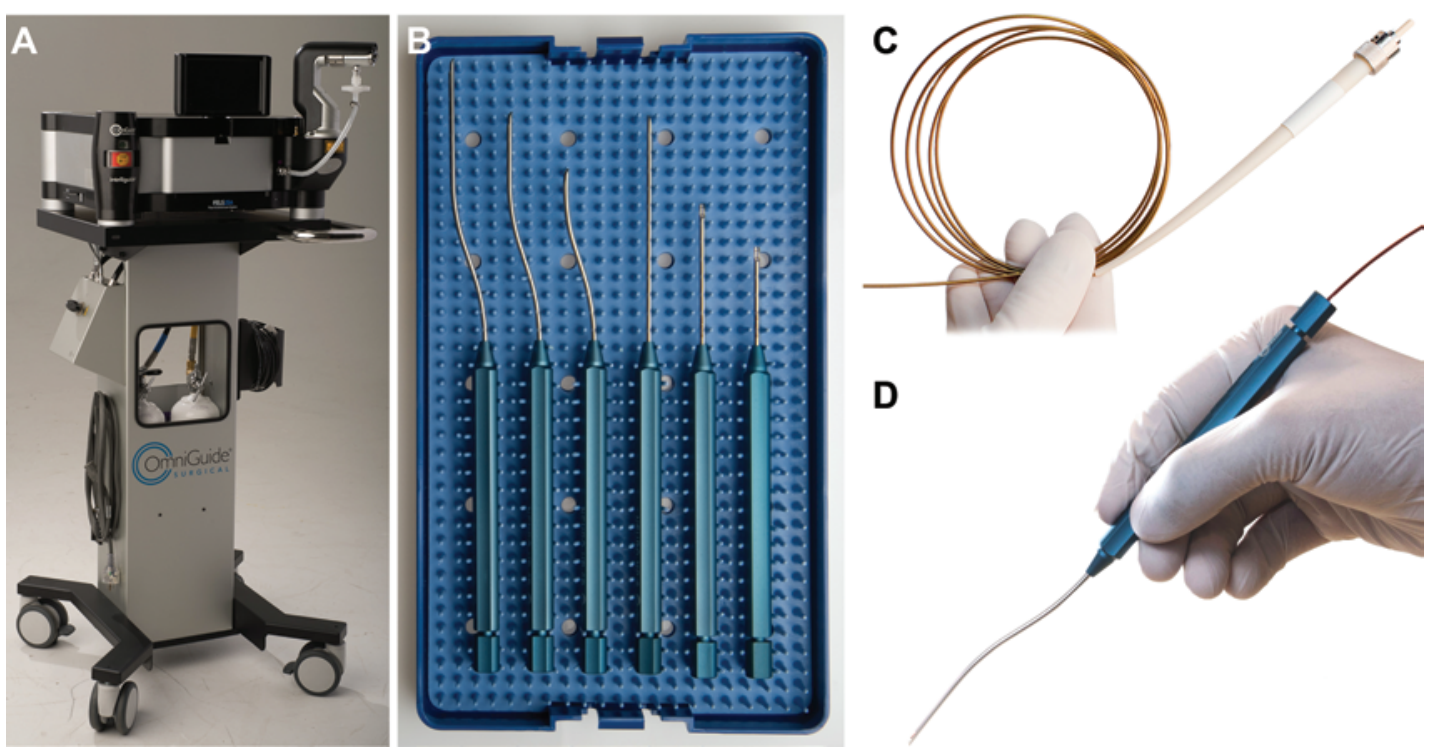

FIG. 2. OmniGuide laser components. A: The OmniGuide laser system, comprising a $\mathrm{CO}_{2}$ source, an adaptor (housing the optical array that passes the laser energy into the fiber), a sterile gas path filter that attaches to the hollow core Neuro $L$ fiber, and a handpiece. B: Handpieces available for the laser, including straight and bayoneted handles of different lengths. C: Neuro-L fiber used for laser corpus callosotomy cases. D: Recommended handgrip for fully assembled OmniGuide laser with a bayoneted handpiece. Images used with permission from OmniGuide Neurosurgical.

well as a foot pedal that applies the laser energy as needed by the surgeon. The laser's "no contact" method makes it easy to work in deeper cavities with minimal tissue destruction.

\section{Operative Technique}

The operative technique employed for a $\mathrm{CO}_{2}$ laser corpus callosotomy is the standard interhemispheric approach using a frontal craniotomy with image guidance (Fig. 3). The patient is positioned supine with the head in a neutral and slightly flexed position. The head is fixed in the Mayfield 3-pin head holder. A craniotomy flap is planned with one-third anterior to the coronal suture and two-thirds behind it (Video 1).

VIDEO 1. Video clip demonstrating intraoperative microscopic exposure of the corpus callosum and laser-assisted callosotomy. Copyright Omar Choudhri. Published with permission. Click here to view with Media Player. Click here to view with Quicktime.

With the neuronavigation system, the midline position is confirmed, and it must be determined that the anterior two-thirds of the corpus callosum may be reached without interference with major bridging veins in the area of the midline approach. The patient's hair is shaved accordingly, and the trapdoor incision spanning the midline is marked.

A skin flap is raised and retained with sutures and a moist flap. Two bur holes are created adjacent to the superior sagittal sinus in the frontal area on each side. The dura mater is carefully detached, especially in the area of the superior sagittal sinus, and then a craniotomy is fashioned.

The dura is opened with the base toward the superior sagittal sinus. Small bridging veins can be coagulated and transected, larger veins are spared. Tacking up the dura allows good access to the interhemispheric fissure, which is prepared by detachment of arachnoid adhesions.

Brain retractors are placed down to the corpus callo- sum. Pericallosal arteries are identified (Fig. 3A) and separated to reach the corpus callosum in the midline (Fig. 3B). Papaverine-soaked cottonoids are used to cover the arteries, which are slightly retracted laterally.

The $\mathrm{CO}_{2}$ laser is set at very low settings for the midline incision of the corpus callosum, usually 4-8 W, and axonal fibers are transected layer by layer. We usually first dissect anteriorly down to identification of the ependymal surface of the lateral ventricle (Figs. 3C-F). The transection is carried anterior to the genu, just shy of the anterior commissure, and the patient is repositioned by dropping the head and moving the retractors slightly more posteriorly. The splenium of the corpus callosum is then sectioned as far posteriorly as possible, in a subpial fashion. After ample irrigation, control of hemostasis is achieved using bipolar cautery.

\section{Discussion}

Corpus callosotomy can help improve the quality of life for patients and their families, but it has had varied success for many types of medically intractable epilepsy. While myoclonic seizures show minimal response to corpus callosotomy, ${ }^{5,12}$ cure rates up to $12 \%$ are reported for generalized tonic-clonic seizures, and cure rates for drop attacks are the highest, with reported rates up to $80 \% .^{21}$ Although mainly palliative, corpus callosotomies have had a diagnostic role as well. In some patients, cessation of the interhemispheric spread of seizures with callosotomy may uncover areas of focal epilepsy, potentially allowing curative treatment with resective epilepsy surgery. Given the palliative role of corpus callosotomy, there have been efforts to make it safer, faster, and better tolerated. Recent efforts have included the use of radiosurgery to create lesions within the corpus callosum.,10

This case series introduces use of the OmniGuide $\mathrm{CO}_{2}$ 

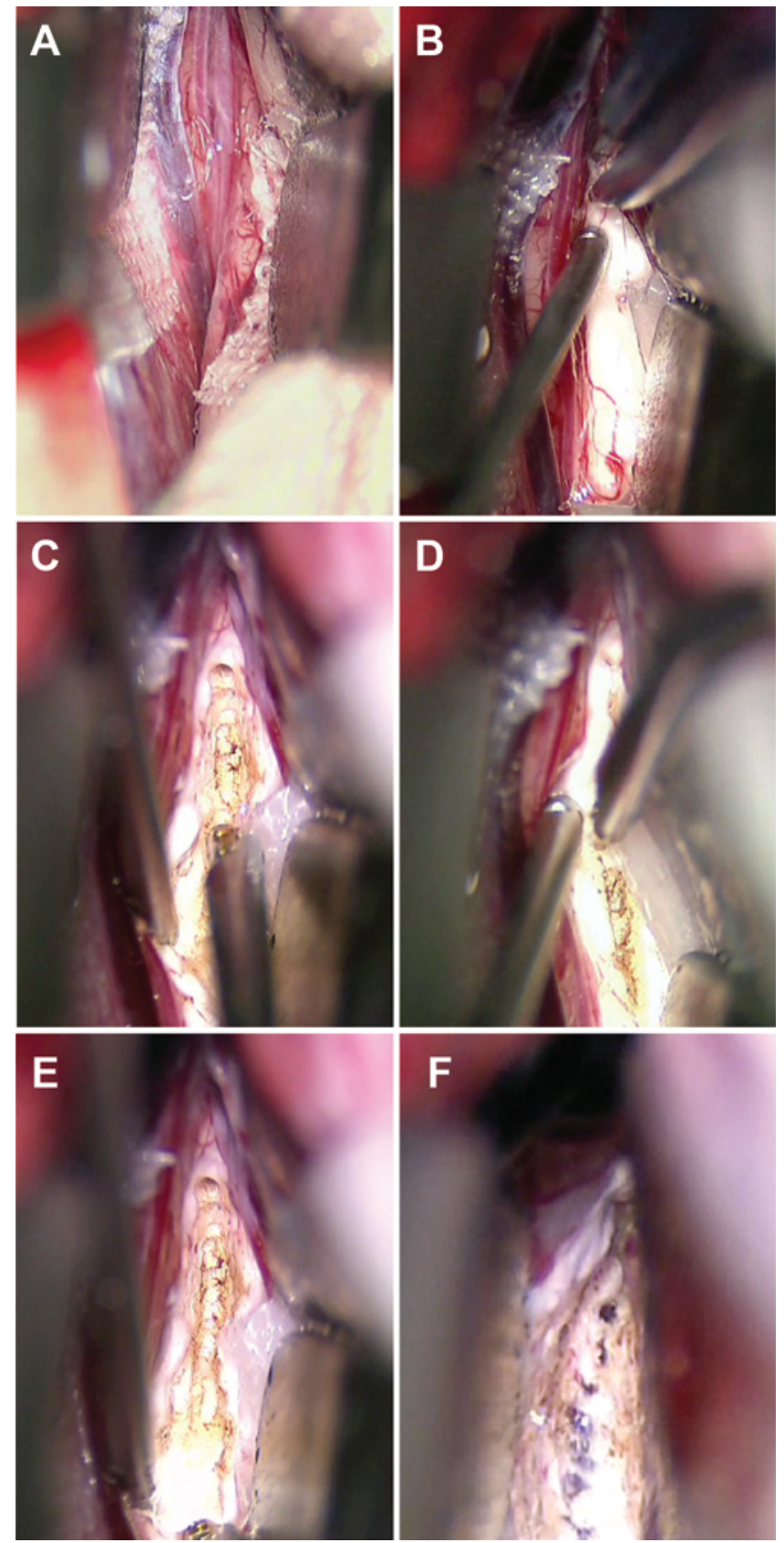

FIG. 3. Intraoperative images demonstrating the steps of laser-assisted corpus callosotomy. A: Interhemispheric approach with brain retractors in place and visualization of pericallosal arteries. B: Dissection completed between the pericallosal arteries to identify the white glistening surface of corpus callosum. C and D: OmniGuide laser being used to coagulate the corpus callosum in a layer-by-layer fashion and a Brackman suction tip (D) used to assist with retraction of pericallosal arteries. E and F: Completed corpus callosotomy, with maintenance of the ependymal plane around the ventricular cavity.

laser to increase callosotomy targeting and precision. This tool has properties of sufficient penetrability and high absorption in water, allowing clean pial incisions with minimal desiccated and edematous areas, as observed in comparison histological specimens treated with bipolar electrocautery. ${ }^{27}$ We have been able to perform diffusion tensor imaging on some of our laser callosotomy patients, with results that demonstrate a clean accurate section of callosal fibers (Fig. 4). The OmniGuide laser handpiece has a narrow profile with a variety of lengths available, which makes it ideal to use in the interhemispheric fissure at a depth of 5-6 cm.

The $\mathrm{CO}_{2}$ laser's "no touch" technique creates no mechanical tissue destruction and causes minimal surrounding thermal injury, which is useful in preventing injury to deeper structures such as the fornix. Additionally, given the laser's low penetration through cerebrospinal fluid, energy delivery ceases almost as soon as it gets near the ventricle. This makes the laser ideal in helping preserve a pial plane during the callosotomy.

The laser creates a clean lesioning plane, which makes it easy to follow to assess progress and when to stop. The laser has both cutting and coagulating properties, ${ }^{26,27}$ and when held farther from the surgical field the laser's coagulating properties can help control pial bleeding. The corpus callosum is generally not very vascularized, and with the addition of the laser there is only minimal bleeding during the procedure. We have not experienced issues with the smoke produced by the laser, as helium gas flow set at 70 psi provides sufficient smoke clearance and fiber cooling. We have experienced shorter operating times in $\mathrm{CO}_{2}$ laser callosotomies, less ventricular hemorrhage, and clean fiber disconnection on tractography (Fig. 4).

The small angled probe of the fiberoptic $\mathrm{CO}_{2}$ laser provided easy access to the midline without risk of resting along the interhemispheric tissue or retraction injury to the right frontal and parietal lobe. Combining image guidance information through the microscope and probe provided excellent localization to the midline and knowledge of the anterior and posterior borders of transaction. With less parasagittal retraction required, these patients will likely experience less postoperative neurological sequelae from the procedure. In order to prevent inadvertent vascular injury, it is important to cover the callosomarginal and pericallosal vessels with irrigated cottonoids while using the laser.

The first reports on the use of this device came from the field of otolaryngology, where it has long been used for tracheal fibromas and head and neck tumors. ${ }^{13}$ Multiple reports have identified the versatility and application of the flexible $\mathrm{CO}_{2}$ laser in neurosurgery for the treatment of a variety of tumors, as well as cavernous malformations and spinal lipomas in tethered cord, and for the prevention of epidural scarring after laminectomy ${ }^{4,19}$ and laser discectomies. ${ }^{20}$ In addition, Jayarao et al. recently reported successful use of the $\mathrm{CO}_{2}$ laser in endoscopic transphenoidal surgery. ${ }^{15}$

One limited technical note has been published on the use of the $\mathrm{CO}_{2}$ suction laser for corpus callosotomy in 2 patients. ${ }^{9}$ In the area of epilepsy surgery there is one published study on use of the $\mathrm{CO}_{2}$ laser for amygdalohipocampectomies in 18 patients with temporal lobe epilepsy. ${ }^{18}$ These papers, however, did not highlight the technical details of device performance or present clinical follow-up data. Our case series describes the use of laser-assisted corpus callosotomy in the pediatric age group and its utility as a technical adjunct in these cases.

The OmniGuide $\mathrm{CO}_{2}$ laser does have some disadvan- 

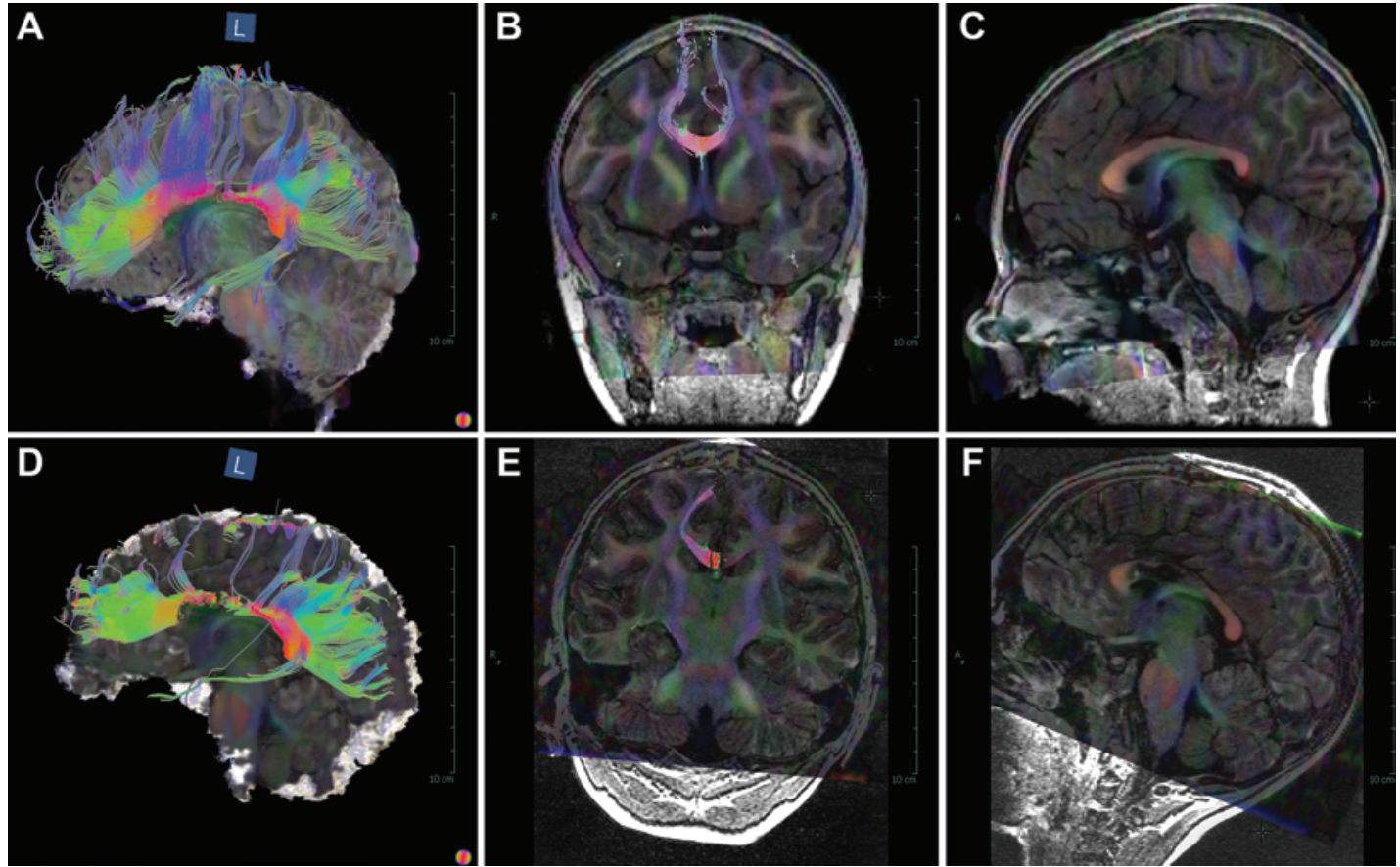

FIG. 4. Diffusion tensor MR images obtained before and after an anterior two-thirds laser-assisted corpus callosotomy. A-C: Preoperative sagittal $(A$ and $C$ ) and coronal $(B)$ images showing robust interhemispheric callosal fiber projections using tractography (A and B) and also denoted as red (left to right directionality) on the color-coded directionality map (A-F). D-F: Postoperative sagittal ( $D$ and $F$ ) and coronal $(E)$ images demonstrating disruption and attenuated appearance of interhemispheric callosal fibers involving the anterior two-thirds of the corpus callosum.

tages. The laser fiber can be used only once and costs approximately $\$ 1500$. The laser is user friendly but does require practice to become proficient. Cleaning the fiber tip requires meticulous care and attention from the operating room staff to avoid damage. The tool could be improved with a handpiece that would allow the surgeon to control wattage and a pointer light that would allow visualization of the target before initiating the laser with the foot pedal.

\section{Conclusions}

Corpus callosotomy is an effective palliative procedure for drop attacks and medically intractable epilepsy. Our case series demonstrates that the OmniGuide $\mathrm{CO}_{2}$ laser is a safe tool when used in combination with traditional microsurgical tools. It helps preserve the ependymal plane, create a clean transection, and minimize surrounding thermal damage to brain tissue. We believe that the $\mathrm{CO}_{2}$ laser can be routinely used to complete corpus callosotomies.

\section{Acknowledgments}

We thank Beth Hoyte for assistance with the figures and Cindy H. Samos for manuscript editing.

\section{References}

1. Asadi-Pooya AA, Sharan A, Nei M, Sperling MR: Corpus callosotomy. Epilepsy Behav 13:271-278, 2008

2. Ascher PW, Heppner F: CO2-Laser in neurosurgery. Neurosurg Rev 7:123-133, 1984

3. Beck OJ: Use of the Nd-YAG laser in neurosurgery. Neurosurg Rev 7:151-157, 1984

4. Browd SR, Zauberman J, Karandikar M, Ojemann JG, Avellino AM, Ellenbogen RG: A new fiber-mediated carbon diox- ide laser facilitates pediatric spinal cord detethering. Technical note. J Neurosurg Pediatr 4:280-284, 2009

5. Cukiert A, Burattini JA, Mariani PP, Câmara RB, Seda L, Baldauf CM, et al: Extended, one-stage callosal section for treatment of refractory secondarily generalized epilepsy in patients with Lennox-Gastaut and Lennox-like syndromes. Epilepsia 47:371-374, 2006

6. Dandy WE: Congenital cerebral cysts of the cavum septum pellucidi (fifth ventricle) and cavum vergae (sixth ventricle): diagnosis and treatment. Arch Neur Psych 25:44-66, 1931

7. Eder HG, Feichtinger M, Pieper T, Kurschel S, Schroettner $\mathrm{O}$ : Gamma knife radiosurgery for callosotomy in children with drug-resistant epilepsy. Childs Nerv Syst 22:1012-1017, 2006

8. Edwards MS, Boggan JE, Fuller TA: The laser in neurological surgery. J Neurosurg 59:555-566, 1983

9. Falowski S, Byrne R: Corpus callosotomy with the $\mathrm{CO} 2$ laser suction device: a technical note. Stereotact Funct Neurosurg 90:137-140, 2012

10. Feichtinger M, Schröttner O, Eder H, Holthausen H, Pieper $\mathrm{T}$, Unger $\mathrm{F}$, et al: Efficacy and safety of radiosurgical callosotomy: a retrospective analysis. Epilepsia 47:1184-1191, 2006

11. Guerrero MH, Cohen AR: Endoscope-assisted microsurgery of the corpus callosum. Minim Invasive Neurosurg 46:5456,2003

12. Hanson RR, Risinger M, Maxwell R: The ictal EEG as a predictive factor for outcome following corpus callosum section in adults. Epilepsy Res 49:89-97, 2002

13. Holsinger FC, Prichard CN, Shapira G, Weisberg O, Torres DS, Anastassiou C, et al: Use of the photonic band gap fiber assembly CO2 laser system in head and neck surgical oncology. Laryngoscope 116:1288-1290, 2006

14. Jalilian L, Limbrick DD, Steger-May K, Johnston J, Powers AK, Smyth MD: Complete versus anterior two-thirds corpus callosotomy in children: analysis of outcome. J Neurosurg Pediatr 6:257-266, 2010 
15. Jayarao M, Devaiah AK, Chin LS: Utility and safety of the flexible-fiber $\mathrm{CO} 2$ laser in endoscopic endonasal transsphenoidal surgery. World Neurosurg 76:149-155, 2011

16. Jea A, Vachhrajani S, Johnson KK, Rutka JT: Corpus callosotomy in children with intractable epilepsy using frameless stereotactic neuronavigation: 12-year experience at the Hospital for Sick Children in Toronto. Neurosurg Focus 25(3):E7, 2008

17. Jea A, Vachhrajani S, Widjaja E, Nilsson D, Raybaud C, Shroff M, et al: Corpus callosotomy in children and the disconnection syndromes: a review. Childs Nerv Syst 24:685692, 2008

18. Kelly PJ, Sharbrough FW, Kall BA, Goerss SJ: Magnetic resonance imaging-based computer-assisted stereotactic resection of the hippocampus and amygdala in patients with temporal lobe epilepsy. Mayo Clin Proc 62:103-108, 1987

19. Killory BD, Chang SW, Wait SD, Spetzler RF: Use of flexible hollow-core $\mathrm{CO} 2$ laser in microsurgical resection of CNS lesions: early surgical experience. Neurosurgery 66:11871192,2010

20. Lee DY, Lee SH: Carbon dioxide (CO2) laser-assisted microdiscectomy for extraforaminal lumbar disc herniation at the L5-S1 level. Photomed Laser Surg 29:531-535, 2011

21. Maehara T, Shimizu H: Surgical outcome of corpus callosotomy in patients with drop attacks. Epilepsia 42:67-71, 2001

22. Oguni H, Olivier A, Andermann F, Comair J: Anterior callosotomy in the treatment of medically intractable epilepsies: a study of 43 patients with a mean follow-up of 39 months. Ann Neurol 30:357-364, 1991

23. Pinard JM, Delalande O, Chiron C, Soufflet C, Plouin P, Kim Y, et al: Callosotomy for epilepsy after West syndrome. Epilepsia 40:1727-1734, 1999

24. Rosomoff HL, Carroll F: Reaction of neoplasm and brain to laser. Arch Neurol 14:143-148, 1966

25. Rougier A, Claverie B, Pedespan MJ, Marchal C, Loiseau P: Callostomy for intractable epilepsy: overall outcome. J Neurosurg Sci 41:51-57, 1997

26. Ryan RW, Spetzler RF, Preul MC: Aura of technology and the cutting edge: a history of lasers in neurosurgery. Neurosurg Focus 27(3):E6, 2009

27. Ryan RW, Wolf T, Spetzler RF, Coons SW, Fink Y, Preul MC: Application of a flexible $\mathrm{CO}_{2}$ laser fiber for neurosurgery: laser-tissue interactions. J Neurosurg 112:434-443, 2010

28. Smyth MD, Klein EE, Dodson WE, Mansur DB: Radiosurgical posterior corpus callosotomy in a child with Lennox-
Gastaut syndrome. Case report. J Neurosurg 106 (4 Suppl): 312-315, 2007

29. Stellar S, Polanyi TG: Lasers in neurosurgery: a historical overview. J Clin Laser Med Surg 10:399-411, 1992

30. Stellar S, Polanyi TG, Bredemeier HC: Experimental studies with the carbon dioxide laser as a neurosurgical instrument. Med Biol Eng 8:549-558, 1970

31. Takizawa T: The carbon dioxide laser surgical unit as an instrument for surgery of brain tumours - its advantages and disadvantages. Neurosurg Rev 7:135-144, 1984

32. Temelkuran B, Hart SD, Benoit G, Joannopoulos JD, Fink Y: Wavelength-scalable hollow optical fibres with large photonic bandgaps for CO2 laser transmission. Nature 420:650-653, 2002

33. Van Wagenen WP, Herren RY: Surgical division of commissural pathways in the corpus callosum: relation to spread of an epileptic attack. Arch Neur Psych 44:740-759, 1940

34. Wong TT, Kwan SY, Chang KP, Hsiu-Mei W, Yang TF, Chen YS, et al: Corpus callosotomy in children. Childs Nerv Syst 22:999-1011, 2006

\section{Author Contributions}

Conception and design: Choudhri, Guzman, Edwards. Acquisition of data: all authors. Analysis and interpretation of data: all authors. Drafting the article: Choudhri, Guzman. Critically revising the article: all authors. Reviewed submitted version of manuscript: all authors. Approved the final version of the manuscript on behalf of all authors: Choudhri.

\section{Supplemental Information Videos}

Video 1, Media Player. http://mfile.akamai.com/21490/wmv/ digitalwbc.download.akamai.com/21492/wm.digitalsource-naregional/peds13-498_video_1.asx.

Video 1, Quicktime. http://mfile.akamai.com/21488/mov/ digitalwbc.download.akamai.com/21492/qt.digitalsource-global/ peds13-498_video_1.mov.

\section{Correspondence}

Omar Choudhri, Department of Neurosurgery, Stanford University School of Medicine, 300 Pasteur Dr., MC5327, Stanford, CA 94305. email: ochoudhri@stanford.edu. 